\title{
Relationship between Heavy Vehicle Speed Limit and Fleet Fuel Consumption on Minor Roads
}

\author{
G. Wilson, G. Morrison, W. Midgley, D. Cebon* \\ Cambridge University Engineering Department, Trumpington St, Cambridge, CB2 1PZ, UK \\ * Corresponding Author: email: dc@eng.cam.ac.uk \\ Accepted for publication in: Proceedings IMechE Part C, Journal of Mechanical Engineering \\ Science, 20 January 2015
}

This research received no specific grant from any funding agency in the public, commercial, or notfor-profit sectors

\begin{abstract}
This paper investigates the traffic-related effects of a proposal to increase the speed limit from $40 \mathrm{mph}$ to $50 \mathrm{mph}$, for Heavy Goods Vehicles (HGVs) greater than 7.5 tonnes, on single carriageway roads. A 'microscopic' single carriageway traffic simulation is developed by combining the 'Enhanced Intelligent Driver Model' with a single carriageway gap-acceptance passing model. Fuel consumption estimates are made using engine characteristic maps and a 'fuel optimal' gear selection scheme, where vehicle trajectories from the traffic simulations are taken as input drive-cycles. Traffic congestion and fleet fuel consumption are specifically addressed, though implications regarding passing behaviour and traffic safety are also noted. Results indicate that the proposed 50mph HGV speed limit would reduce traffic congestion by over $37 \%$ and increase fleet fuel consumption by approximately $0.5 \mathrm{~L} / 100 \mathrm{~km}$.
\end{abstract}




\section{Background}

\subsection{Introduction}

The Department for Transport (DfT) in the UK currently imposes a 40mph speed limit for heavy goods vehicles (HGVs) greater than 7.5 tonnes on single carriageway roads (also known as two-lane, two-way highways). As seen in Table 1, this limit makes HGVs the most speed-restricted vehicles on single carriageways.

\begin{tabular}{cc}
\hline Vehicle Class & Single Carriageway Speed Limit (mph) \\
\hline Cars, Motorcycles, and Vans less than 2 tonnes & 60 \\
Cars and Vans Towing Trailers & 50 \\
Buses, Coaches, and Mini-Buses & 50 \\
Goods Vehicles Less than 7.5 tonnes & 50 \\
Goods Vehicles Greater than 7.5 tonnes & 40 \\
\hline
\end{tabular}

Table 1: Single carriageway speed limit by vehicle class.

On November $9^{\text {th }}, 2012$, the DfT issued a consultation to evaluate the effects of increasing the speed limit for HGVs from $40 \mathrm{mph}$ to $50 \mathrm{mph}$, and from $40 \mathrm{mph}$ to $45 \mathrm{mph}$ (1). The consultation gave several arguments in favour of a new, higher HGV speed limit: "...the current $40 \mathrm{mph}$ speed limit causes unnecessary cost to vehicle operators, congestion, avoidable overtaking collisions and creates an uneven playing field for businesses". Road freight operators widely supported these claims, emphasizing that the current speed limit restricts the sector's overall economic production. However, critics argue that the proposed new speed limits would reduce road safety. The Royal Society for the Prevention of Accidents argues that a higher HGV speed limit would lead to "...more, and more severe, road accidents and casualties" involving HGVs (2). The added cost of such accidents could more than offset the economic benefits associated with shorter journey times. Other issues, such as increased risk to cyclists, road maintenance, and noise pollution, were also cited as undesirable consequences of a higher HGV speed limit.

Over the course of the consultation period, several organizations attempted to measurably evaluate these concerns. This work addresses two important, yet overlooked topics with respect to these studies: traffic congestion, and fuel consumption.

The objectives of this study were:

1) To developing a single carriageway traffic model representative of UK roads.

2) To evaluate the effects of the proposed HGV speed limit on traffic congestion and fuel consumption using this model. 


\subsection{Literature Review}

\section{Traffic Flow Theory}

Traffic behaviour is often modelled using 'single regime' (i.e. single equation) speed-flow curves. Greenshields (3) conceived the first of these curves, the "Fundamental Diagram", by proposing a linear correlation between the average fleet travel speed and traffic density. Further studies have been conducted to develop more accurate speed-flow relationships, with the most success coming from multi-regime models (4). Researchers have also attempted to qualitatively represent all traffic flows. Kerner \& Rehborn (5) proposed three phases: free-flow, synchronized flow and wide moving jam flow which correspond to low, medium, and high traffic densities, respectively. Their research introduced the unstable phenomena of stop-and-go waves, also known as wide-moving jams, which develop at midhigh densities and propagate upstream. While popular, the three phase model provides a simplistic view of traffic behaviour. Trieber et al. (6) discovered that two-phase models, at a certain level of specification, could sufficiently replicate three-phase model behaviour.

\section{Traffic Modelling}

Traffic modelling attempts to capture the interactions between vehicles, drivers and infrastructure. Traffic models typically fall into two categories: 1) macroscopic continuum models, and 2) microscopic models. Macroscopic continuum models assess bulk traffic flow characteristics such as density, flow, and mean velocities using equations typically derived from fluid mechanics. Microscopic traffic models typically simulate the behaviour of each individual vehicle within a system, ideally producing accurate macroscopic results when integrated. The specificity of microscopic models allows for high resolution simulations, although this comes at a high computational cost. Past research has focused most heavily on developing car-following models - a closed form set of equations that describes how a specific vehicle follows its leader. Additional models, such as intersection, merging, twolane, and passing models, are typically combined with car-following models to simulate more complex traffic interactions.

Optimal Velocity Models (OVMs) are perhaps the most popular class of microscopic carfollowing models. Accelerations are calculated as a function of the vehicle's 'optimal velocity' - related to the driver's headway - and its current speed (7). According to Orosz et al. (8), OVMs "can reproduce qualitatively almost all kinds of traffic behaviour and also transitions between." The inclusion of a sensitivity parameter also allows for heterogeneity in driver characteristics. One difficulty with OVMs relates to their underlying parameters. According to Wagner (9), many of the principal OVM parameters, such as relaxation time, take on unrealistic values in order for the model to match real data.

The Intelligent Driver Model (IDM) has become popular more recently, and combines several driving strategies into one complete, crash-free car-following acceleration function. 
Kesting et al. (10) note that "the IDM parameters...have a reasonable interpretation, are known to be relevant, are empirically measurable, and have realistic values." An extension to the IDM, known as the Enhanced IDM model (ACC), is also available to safeguard realistic behaviour after 'cut-in' manoeuvres. This enhanced model was used in a recent study by Morrison et al. (11) to investigate the effects of heavy vehicle size on traffic congestion and fuel consumption.

\section{Single Lane Passing Models}

Single carriageway passing behaviour has been understood quantitatively using various 'passing gap acceptance' models. Farah et al.(12) proposed that the conditional probability of completing a passing manoeuvre is equal to the product of 'desire to pass' and 'gap acceptance' probability functions. Their model included road specific and driver-specific parameters such as road curvature, leading vehicle speed, driver age, skill, and aggressiveness. More recently, Ghods (13) modelled the decision to overtake as a function of the driver's perceived 'time to collision' (TTC) with the oncoming vehicle after it has returned to its travel lane. The TTC is a combined variable: it accounts for the speeds and positions of the leading vehicle, oncoming vehicle, and overtaking vehicle. Validation against single carriageway data showed that the TTC model outperformed TWOPAS, a leading commercial simulator, in simulating single carriageway behaviour (13).

\section{Fuel Consumption Modelling}

Fuel consumption models typically require trajectory input information - either from a prescribed drive-cycle or a microscopic simulation. This information is often passed into a power balance from which fuel consumption estimates can be made (14). Various calculated regressions exist for fuel consumptions (and emissions) modelling (15). However, these regressions assume steady velocity profiles, thus failing to capture any transient behaviour. More effective results are obtained through the combined use of engine maps with gear selection schemes. Hunt et al. (16) employed gear changes based upon allowable engine speeds, whereas Treiber et al. (17) considered a 'fuel-optimal' gear selection scheme.

\section{Traffic Model}

\subsection{Model Development}

A microscopic traffic model was developed by combining the Enhanced Intelligent Driver model (Enhanced IDM) (10) with the Time to Collision single carriageway passing model (13). Figure 1 illustrates the model's structure. Simulations were conducted using a closed 'loop' road layout in the sense that vehicles crossing the end of the road reappear at the beginning in a continuous fashion. However, to the individual vehicles, the road has a straight, level geometry. 
The following sections detail the development process of the single carriageway model.

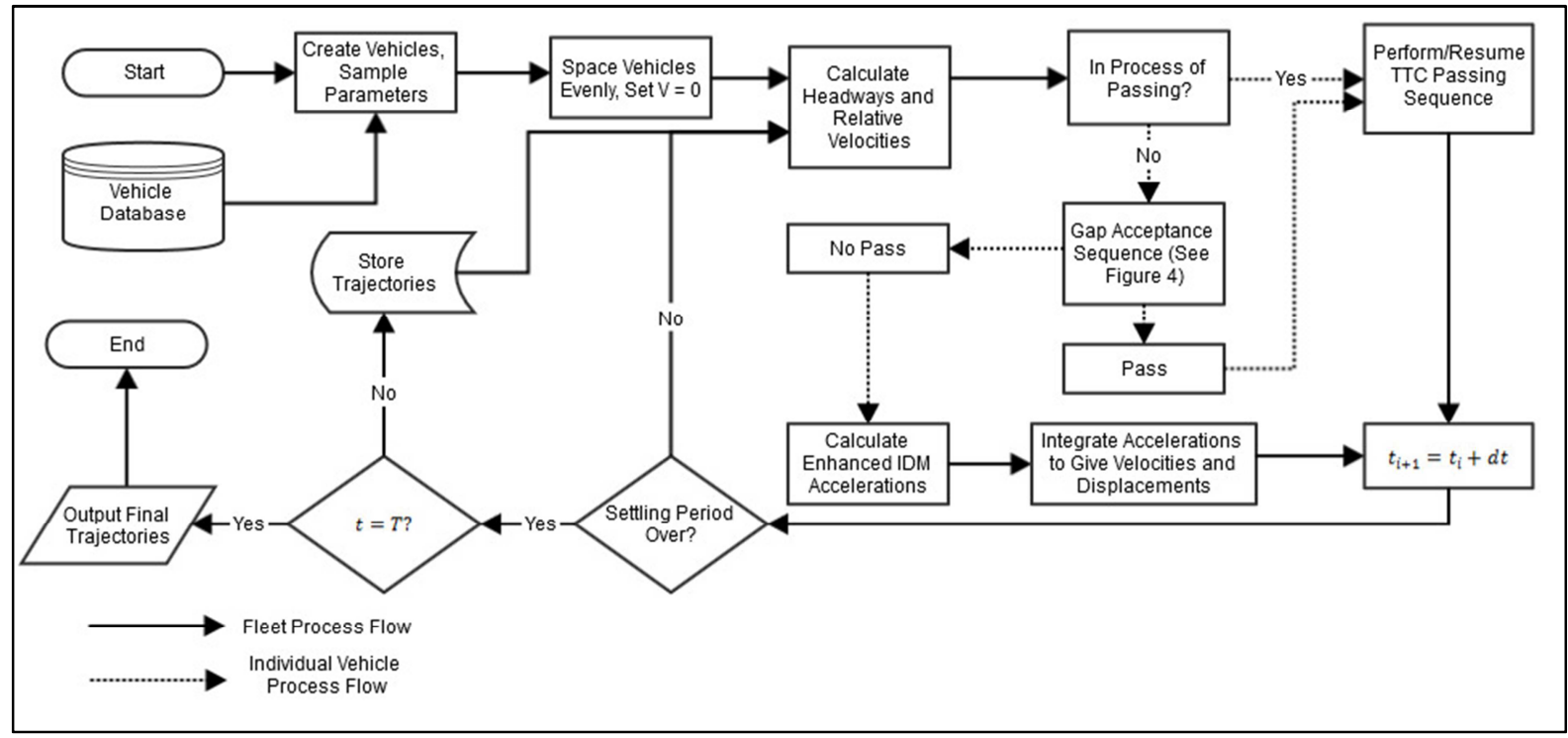

Figure 1: Process flow diagram for the single carriageway model.

\section{Intelligent Driver Model (IDM)}

The core of the model is the microscopic, single lane, Enhanced IDM car-following model (10), which is based on the standard IDM equation:

$$
a_{I D M}(s, v, \Delta v)=a\left[1-\left(\frac{v}{v_{o}}\right)^{\delta}-\left(\frac{s_{0}+v T+\frac{v \Delta v}{2 \sqrt{a b}}}{s}\right)^{2}\right]
$$

where the parameters are defined in Table 2. The first two terms of Equation 1 represent a free-road acceleration strategy while the last term represents a car-following acceleration strategy.

\begin{tabular}{cc}
\hline Parameter & Definition \\
\hline $\boldsymbol{a}$ & Maximum Acceleration \\
$\boldsymbol{v}$ & Instantaneous Velocity \\
$\boldsymbol{v}_{\boldsymbol{o}}$ & Desired Velocity \\
$\boldsymbol{\delta}$ & Free-Acceleration Exponent \\
$\boldsymbol{s}_{\mathbf{0}}$ & Jam Distance \\
$\boldsymbol{T}$ & Desired Time Headway \\
$\boldsymbol{s}$ & Instantaneous Headway \\
$\Delta \boldsymbol{v}$ & Relative Velocity to Leading Vehicle \\
$\boldsymbol{b}$ & Comfortable Deceleration \\
\hline
\end{tabular}

Table 2: Standard IDM parameter definitions.

The Enhanced IDM is used to calculate the acceleration of each vehicle in the traffic stream at each simulation time step. These accelerations are integrated to give the velocity and position of every vehicle. (The single lane Enhanced IDM model was verified by Wilson et al. (18) to behave in accordance with stop-and-go wave theory (5) and Greenshields' general principles (3).) 
In most scenarios, the Enhanced IDM model reduces to the standard IDM model shown in Equation 1. The extended features of the Enhanced IDM only become significant during 'cut in' manoeuvres associated with passing and lane-changing (10).

\section{Extension to Include Passing}

The passing model considers the scenario in Figure 2. A following vehicle (FV) wants to overtake a leading vehicle (LV) with some distance or 'passing gap' to an opposing vehicle (OV). The decision to overtake is a function of the relative positions, velocities, and driver specific parameters of these three vehicles.

The model uses the Time to Collision passing framework conceived by Ghods (13). The FV's decision to overtake a LV is based on the FV's perceived 'time to collision' (TTC) with the OV at the instant that it has returned to its travel lane (Figure 3). If the estimated TTC gap is greater than the FVs threshold gap (TTC $C_{\text {crit }}$ ) then the $\mathrm{FV}$ is eligible to initiate a passing manoeuvre.

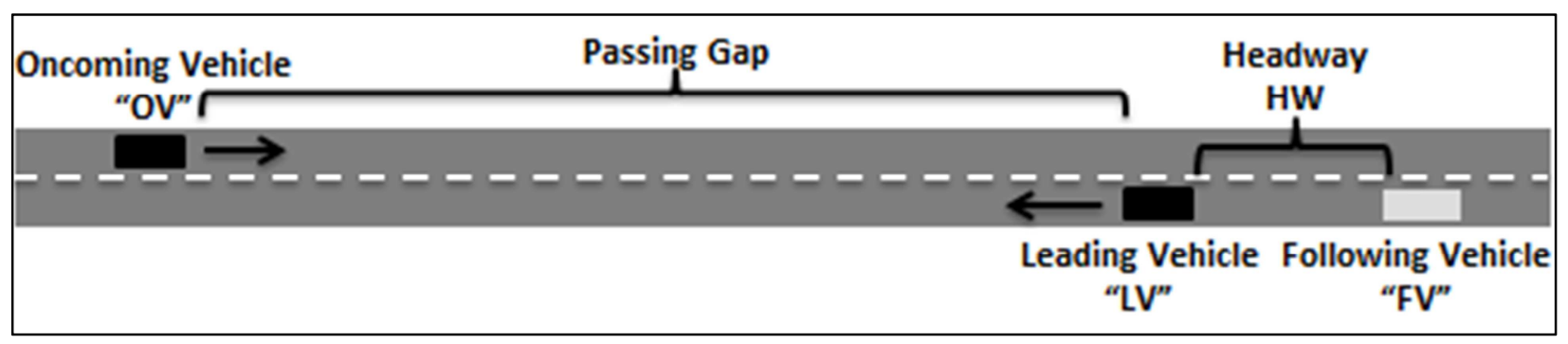

Figure 2: Single carriageway passing scenario.

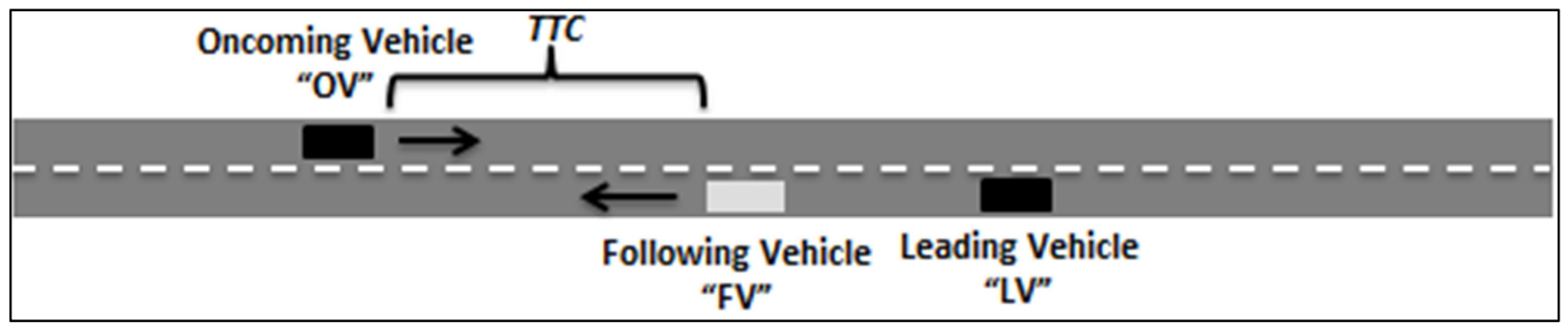

Figure 3: The remaining time to collision after the FV has overtaken the LV.

\section{Calculation of TT}

To calculate the TTC, the passing manoeuvre is broken down into four sequential phases (from (13)):

- Phase 1 - Distance travelled by the FV from 'desire to overtake' to 'pull-out' $\left(D_{1}\right)$.

- Phase 2 - Distance travelled by the FV from 'pull-out' to the point where desired overtaking speed is achieved $\left(D_{2}\right)$.

- Phase 3 - Distance required to achieve safe separation headway (with the LV) prior to pull-back $\left(D_{3}\right)$.

- Phase 4 - Distance travelled during pull-back $\left(D_{4}\right)$. 
It is assumed that the LV and OV travel at constant speeds throughout the manoeuvre; a common assumption used in passing models (19). The full TTC calculation procedure is not detailed here. Slight changes were made to the original procedure in Ghods (13), the details and justifications of which are presented by Wilson et al. (18).

\section{Gap Acceptance}

In the event that $T T C>T T C_{\text {crit }}$, a driver's likelihood of initiating a passing manoeuvre is modelled by a gap acceptance probability function. The probability that a particular driver $j$ will accept a given TTC gap is expressed as:

$$
P_{j}(\text { Accept } T T C)=\phi\left(\frac{T T C-\overline{T T C}_{c r i t}}{\sigma}\right)
$$

where $\phi$ represents the standard cumulative normal curve or 'Probit function', and $\sigma$ represents the standard deviation of $T T C_{c r i t}$. Equation 2 signifies that drivers are more likely to accept large passing gaps over smaller ones, and is evaluated the moment a passing gap becomes available. Drivers that reject a particular gap do not have the opportunity to overtake until a new gap becomes available.

The gap acceptance sequence presented by Ghods (13) was extended in order to maintain realistic and crash-free driving behaviour when combined with the Enhanced IDM (Figure 4, where additional criteria are presented in bold). Drivers of vehicles that satisfy all of the passing criteria in Figure 4 will accept their gap, and initiate a passing manoeuvre.

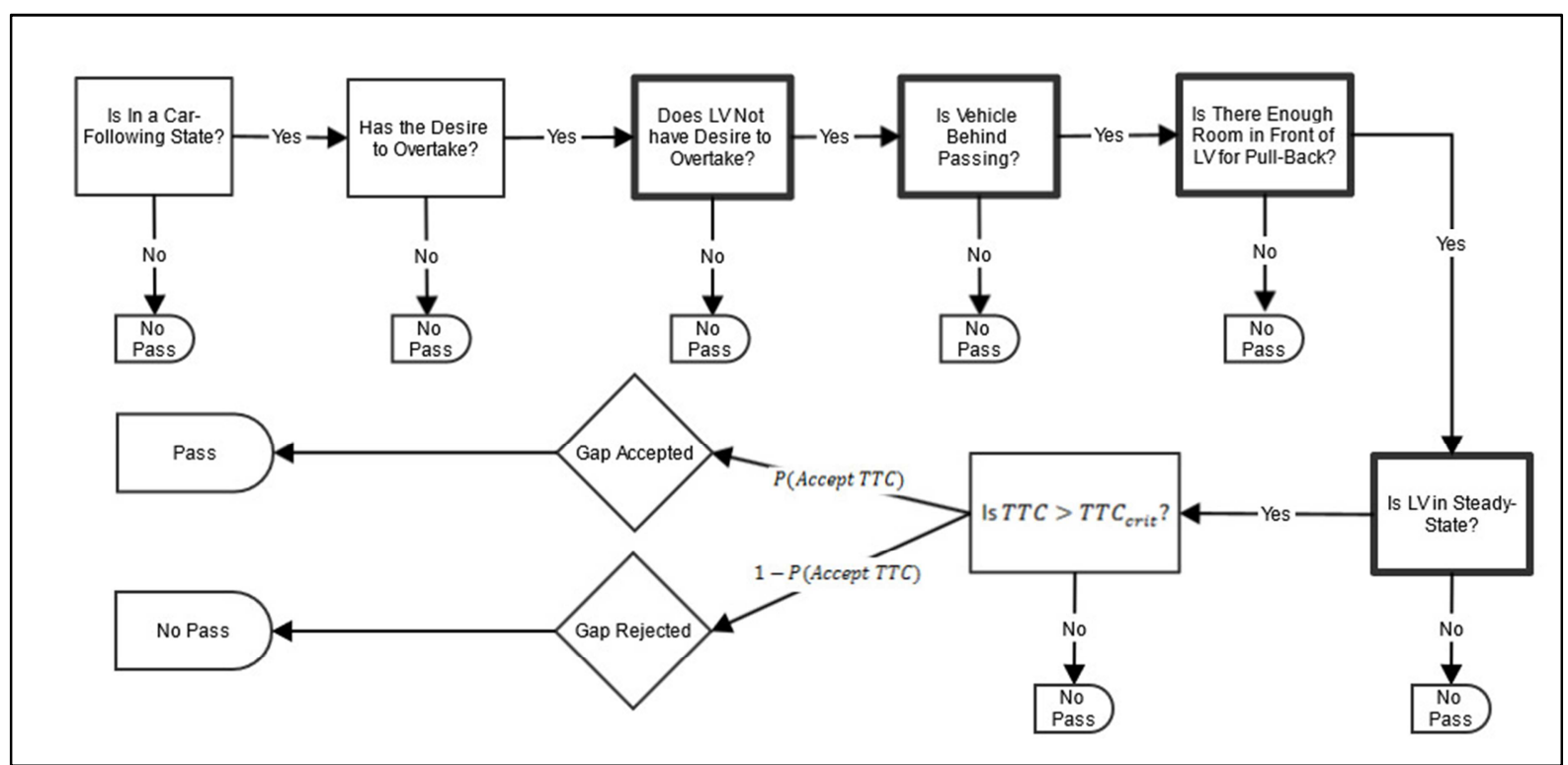

Figure 4: Enhanced decision tree used to evaluate passing manoeuvres in the single carriageway model. Supplementary conditions to those used by Ghods (13) are highlighted in bold. 


\subsection{Model Parameters}

A complete list of traffic model parameters is presented in Appendix A. The justifications used to implement some of these parameters are detailed below.

\section{Target Velocities}

Normal distributions were fitted to free flow velocity data published by the UK's Department for Transport (DfT) (20). These distributions were randomly sampled to give the desired velocity parameter $v_{0}$ (required by the Enhanced IDM) for each simulated vehicle.

\section{Maximum Acceleration}

The maximum acceleration parameter is defined slightly differently between the Enhanced IDM and TTC models. To maintain consistency, maximum accelerations of $1.4 \mathrm{~m} / \mathrm{s}^{2}$ for cars and vans and $0.7 \mathrm{~m} / \mathrm{s}^{2}$ for HGVs were taken from Kesting et al. (10).

\section{Desired Overtaking Velocity}

The fixed desired overtaking velocity of $29.2 \mathrm{~m} / \mathrm{s}$ suggested by Ghods (13) does not represent the conditional nature of passing. To correct for this, a desired overtaking velocity equal to $4.2 \mathrm{~m} / \mathrm{s}$ higher than the LV velocity is used, as proposed by Kim \& Elefteriadou (21).

\subsection{Calibration \& Validation}

\section{Data}

Both calibration and validation of the model were performed using single carriageway traffic data collected for UK roads. The DfT collects speed and traffic flow data for thousands of road links throughout the UK (22). Suitable links (e.g. single carriageway rural roads with few intersections) were difficult to find within this database; however, five links were discovered with suitable characteristics. Table 3 provides information regarding the five chosen links. 


\begin{tabular}{|c|c|c|c|c|c|}
\hline Road Link & AL1331 & AL1346 & AL1348 & AL1798 & AL1806 \\
\hline Description & $\begin{array}{l}\text { A628 between } \\
\text { A57 and } \\
\text { A6024 }\end{array}$ & $\begin{array}{c}\text { A36 between } \\
\text { A303 and } A 361\end{array}$ & $\begin{array}{l}\text { A36 between } \\
\text { A361 and A36 }\end{array}$ & $\begin{array}{l}\text { A259 between } \\
\text { A268 and A259 }\end{array}$ & $\begin{array}{l}\text { A2070 between } \\
\text { A259 and } \\
\text { A2042 }\end{array}$ \\
\hline Length (km) & 10.3 & 28.3 & 17.7 & 13.8 & 14.7 \\
\hline $\begin{array}{c}\text { Percentage of } \\
\text { Road with More } \\
\text { Than One } \\
\text { Directional Lane } \\
(\%) \\
\end{array}$ & 0 & 3.2 & 6.3 & 10.9 & 0 \\
\hline $\begin{array}{c}\text { Number of } \\
\text { Roundabouts }\end{array}$ & 0 & 4 & 1 & 0 & 2 \\
\hline $\begin{array}{c}\text { Number of Traffic } \\
\text { Lights }\end{array}$ & 0 & 0 & 1 & 0 & 0 \\
\hline $\begin{array}{c}\text { Max Directional } \\
\text { Flow Rate } \\
\text { (Veh/hr) }\end{array}$ & 687 & 795 & 1912 & 470 & 772 \\
\hline $\begin{array}{c}\text { Percentage of } \\
\text { Road with } \\
\text { Restrictive Speed } \\
\text { Zones (\%) } \\
\end{array}$ & 65.0 & 6.7 & 31.1 & 46.4 & 0.1 \\
\hline $\begin{array}{c}\text { Percentage of } \\
\text { Road with Passing } \\
\text { Restrictions (\%) }\end{array}$ & 61.7 & 28.2 & 37.9 & 12.3 & 16.3 \\
\hline $\begin{array}{c}\text { Unusual Road } \\
\text { Conditions }\end{array}$ & None & None & None & Hairpin Turn & None \\
\hline
\end{tabular}

Table 3: Summary of road link properties and features.

Among these road links, AL1348 was selected for calibration purposes due to its relatively high vehicle flow rates. This allowed the single carriageway model to be calibrated under a wide range of traffic conditions. The remaining four road links were used for validation purposes after the model had been calibrated.

\section{Additional Considerations}

The prevalence of $40 \mathrm{mph}$ and $30 \mathrm{mph}$ speed limits and no-passing zones in all of the road links necessitated that these features be implemented into the model. In restrictive speed zones, the target velocities of all vehicles were adjusted to meet the observed values presented in the DfT free-flow SPE0102 file (23). The model also simulates each link's nopassing zones - these were identified from aerial photographs for each lane as places along the road with a solid near-side centreline marking (illegal passing was not considered). Other road features, such as grades, curves, traffic lights and roundabouts, were ignored.

\section{Parameter Study}

Simulations were conducted with each IDM parameter varied individually by up to $\pm 30 \%$. The IDM variables that were found to have a considerable impact on the 'fundamental diagram' (i.e. Greenshield's chart of vehicle flux vs. mean vehicle speed (3)) were $T$ and $v_{0}$. Furthermore, as observed by Morrison et al. (11), these variables have seemingly independent effects on the model. The study also considered varying the standard deviation 
of $v_{0}$. Results indicated that narrow distributions generate steeper, less scattered fundamental diagrams in the free-flow region, whereas wide distributions generate gradual, more scattered diagrams. Lastly, the effects of passing were evaluated with respect to the model's fundamental diagram. The results from this study are detailed in Wilson et al. (18).

\section{Calibration}

Figure 5 depicts both the baseline (pre-calibrated) and calibrated models in comparison with the AL1348 data. In the pre-calibrated simulation, measured free-flow velocities for single carriageway roads, provided by the DfT, were used for the 'desired velocity' parameter $v_{0}$ and its standard deviation. The time headways $T$ were those suggested by Kesting et al. (10). It can be seen that the pre-calibrated model (red circles) does not fit the measured data (blue dots) well.

The measured free-flow velocities were found to underestimate the values of $v_{0}$ needed to match the measured fundamental diagram for the traffic stream. This is probably because the DfT data was an average over many road links and was therefore collected under 'nonideal' conditions - e.g. road links having curves, hills, or not being completely clear. The measured value for cars and vans $(48 \mathrm{mph})$ was therefore increased by $30 \%$ to give a desired velocity $v_{0}$ slightly above the $60 \mathrm{mph}$ speed limit. Similarly, the measured standard deviation of the free-flow velocities was reduced to provide the standard deviation of $v_{0}$. This gave values that more closely matched observations made by Nezamuddin et al. (24).

The time headways $T$ suggested by Kesting et al. (10) were also reduced by $33 \%$. This resulted in cars, vans and HGVs having desired headways of $1 \mathrm{~s}, 1 \mathrm{~s}$, and $1.3 \mathrm{~s}$, respectively. According to Martin (25), realistic values of $T$ vary between $0.8 \mathrm{~s}$ and $2 \mathrm{~s}$.

The pre- and post- calibration values of the key parameters are displayed in Table 4. The calibrated model (black diamonds in Figure 5) fits the measured data well. 


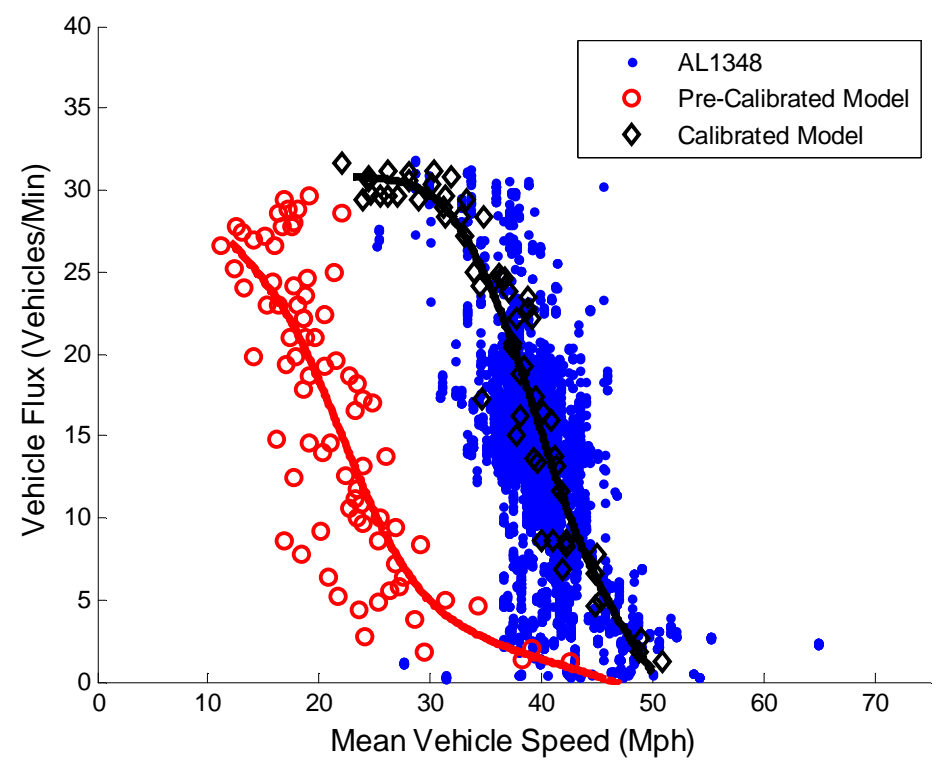

Figure 5: 'Fundamental Diagram' of measured and simulated traffic flows for pre-calibrated (baseline) and calibrated traffic model for link AL1348.

\begin{tabular}{|c|c|c|}
\hline Parameter & Baseline Value & Calibrated Value \\
\hline $\begin{array}{l}\text { Mean } v_{0} \text { for Cars } \\
\text { and Vans at National } \\
\text { Limit (mph) }\end{array}$ & 48.0 & 62.4 \\
\hline $\begin{array}{c}\text { Mean } v_{0} \text { for Cars and } \\
\text { Vans at } 40 \mathrm{mph} \text { Limit } \\
\text { (mph) }\end{array}$ & 35.0 & 42.0 \\
\hline $\begin{array}{c}\text { Standard Deviation of } v_{0} \\
(\mathrm{mph})\end{array}$ & $\begin{aligned} \text { Cars: } & 9.5 \\
\text { Vans: } & 9.9 \\
\text { Trucks: } & 9.6\end{aligned}$ & $\begin{aligned} \text { Cars: } & 4.3 \\
\text { Vans: } & 4.5 \\
\text { Trucks: } & 4.3\end{aligned}$ \\
\hline $\begin{array}{c}\text { Desired Time Headways } T \\
\text { (sec) }\end{array}$ & $\begin{aligned} \text { Cars: } & 1.5 \\
\text { Vans: } & 1.5 \\
\text { Trucks: } & 2.0\end{aligned}$ & $\begin{aligned} \text { Cars: } & 1.0 \\
\text { Vans: } & 1.0 \\
\text { Trucks: } & 1.3\end{aligned}$ \\
\hline
\end{tabular}

Table 4: Parameter values that were adjusted during the calibration process.

\section{Validation}

The calibrated single carriageway model was tested against data from the remaining four road links. As discussed above, these roads differ with respect to their speed limits, lengths, and passing opportunities. Their maximum flow rates, however, are all distinctively low. This validation process therefore tested the model's ability to simulate road features (e.g. passing lanes, speed limits) and low-density traffic flow behaviour.

Figure 6 compares the simulated fundamental diagram against speed-flow data for the four road links. The model performs accurately despite the wide range of simulated conditions ${ }^{1}$.

\footnotetext{
${ }^{1}$ The calibrated model data for links AL1331 and AL1798 is less scattered due to the higher presence of 30mph and $40 \mathrm{mph}$ speed limit zones, which act to narrow fleet $v_{0}$ distributions.
} 
The model provides slightly high velocity estimates in links AL1331 and AL1798. These discrepancies are likely a result of the model's road implementation assumptions (e.g. curves and shoulders are neglected). However, in general, the model provides accurate speed-flow estimates for single carriageway roads.

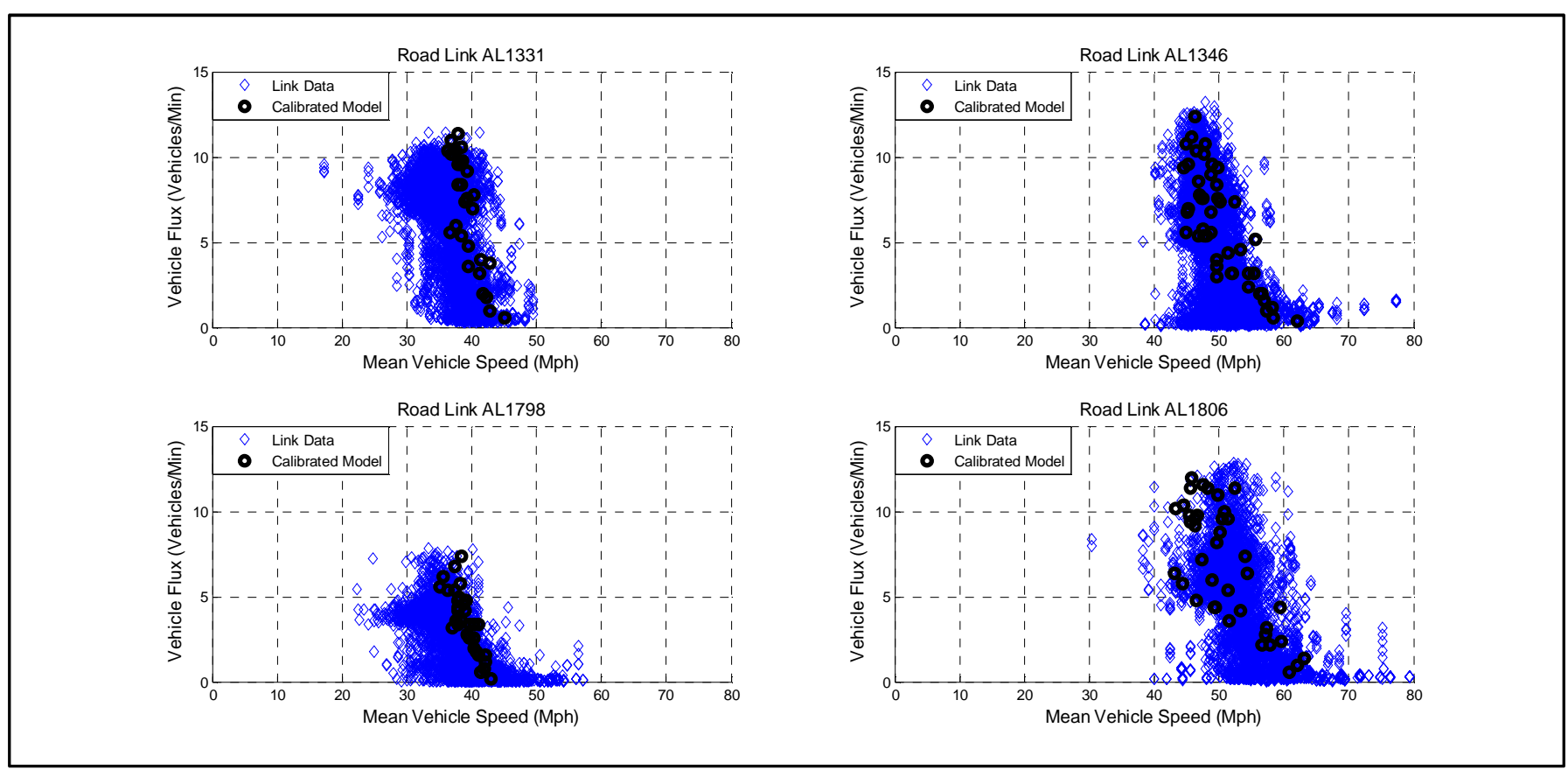

Figure 6: Validation of the single carriageway model against four UK single carriageway road links. 


\section{Fuel Consumption Model}

Figure 7 outlines the basic structure of the fuel consumption model.

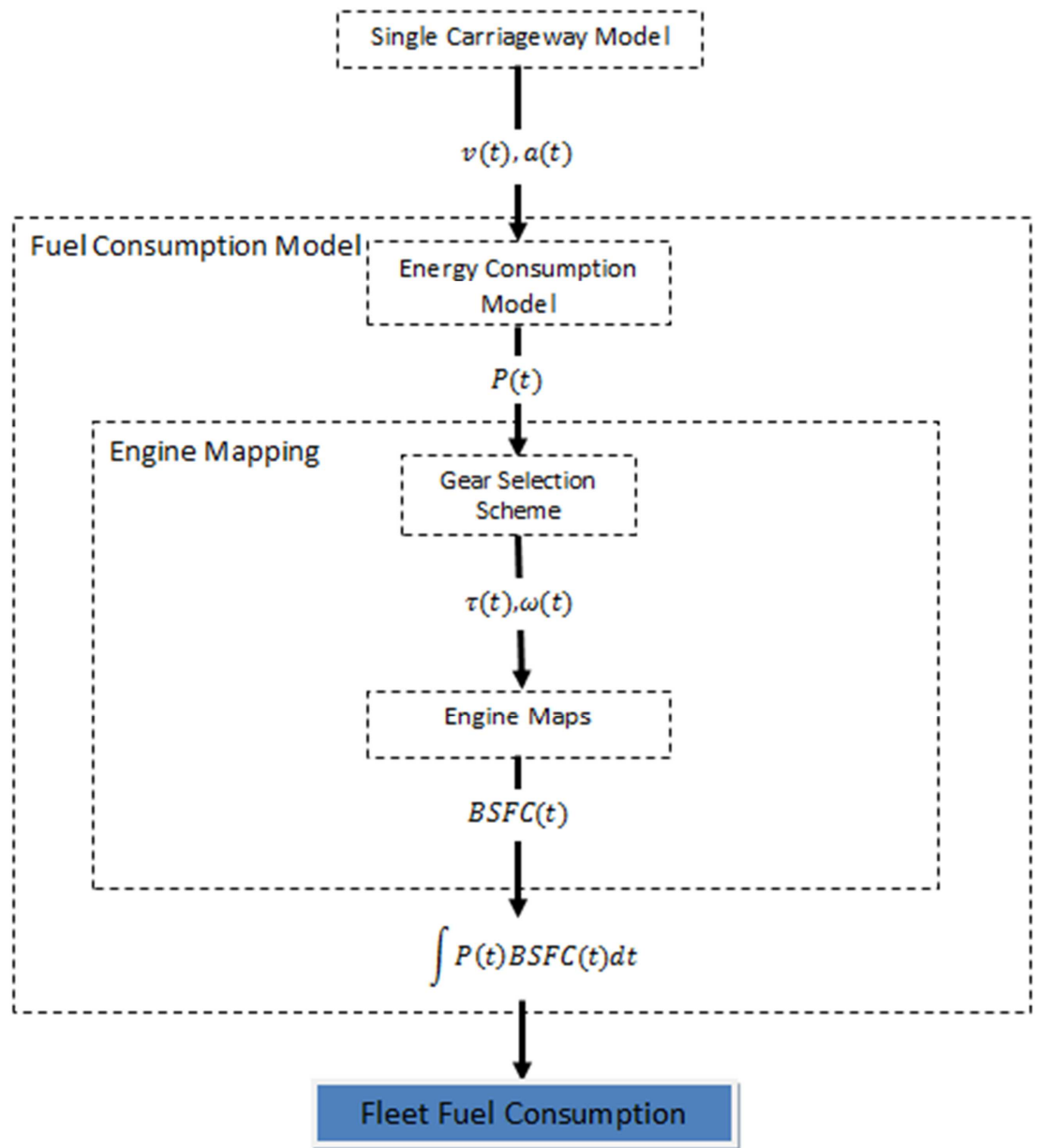

Figure 7: General flow diagram of the fuel consumption model.

\section{Energy Consumption Model}

The energy model computes vehicular power consumption by post-processing the simulated trajectory data. The model considers the major, relevant forces that act on moving vehicles: accessory losses (e.g. air conditioning, lights), aerodynamic drag, rolling resistance, transmission losses and inertial forces. Gravitational drag force was neglected here because all roads were assumed to be flat. Each term of the model's energy balance is detailed below (11).

Accessories loss:

$$
P_{a c c}=P_{0}
$$

Aerodynamic drag:

$$
P_{\text {drag }}=\frac{1}{2} c_{D} A \rho v^{3}
$$

Rolling Resistance:

$$
P_{\text {roll }}=m g v\left(\mu_{0}+\mu_{1} v^{2}\right)
$$

Acceleration Power:

$$
P_{\text {inertia }}=\operatorname{mav}
$$


Total Demanded Power: $\quad P=P_{\text {acc }}+\frac{1}{\eta_{t}}\left(P_{\text {drag }}+P_{\text {roll }}+P_{\text {interia }}\right)$

A complete list of the energy model parameters is available in Appendix B.

\section{Engine Mapping Structure}

The fuel consumption model performs engine mapping at the output of the energy model. The demand power $P$ developed in Equation 7 is broken down into a demand torque $\tau$ and demand speed $\omega$ using equations 8 and 9, respectively:

$$
\begin{gathered}
\tau=\frac{1}{G}\left(\frac{P}{v} r_{d y n}\right) \\
\omega=G\left(\frac{v}{r_{d y n}}\right)=\frac{P}{\tau}
\end{gathered}
$$

where $G$ is the gear ratio, $r_{d y n}$ is the dynamic tyre rolling radius, and $v$ is the vehicle speed. The torque and speed produced by the engine will vary in accordance with the selected gear. However, by definition, their product will always equal the demanded power.

$\tau$ and $\omega$ are then passed into the vehicle's engine map. Using a lookup table, the engine map generates the associated brake specific fuel consumptions (BSFC) - an efficiency metric

with units $g_{f u e l} / k W h$ - by interpolating at the given engine $(\tau, \omega)$ operating conditions. From this, fuel consumption rates are easily found (17).

\section{Engine Maps}

Vehicle manufacturers do not normally publish their (confidential) engine data - it is scarce in the open literature. This significantly limits the availability of accurate and relevant engine maps. Only four relevant original engine maps could be found and a fifth engine map was produced by scaling one of these four maps. These five maps were used to represent all vehicles in the UK fleet.

Three engine maps were selected to represent the distribution of car engines within the fleet: a 1.0L (Petrol) 'Geo Metro' map, a 1.9L (Petrol) 'Saturn' map, and a 2.0L (Diesel) 'VW Jetta' map. Each map was assumed to represent one or more of the most popular classes of UK cars - these classes were approximated using the Society of Motor Manufacturers and Traders (SMMT) new car registration data over the past ten years (26).

By contrast, vans and HGVs were assumed to have homogenous engine types, as only a few heavy vehicle engine maps were found. All HGVs were assumed to use a Cummins M11 $246 \mathrm{~kW} \mathrm{Cl}$ engine, whereas all vans were assumed to use a scaled version of the Jetta $2.0 \mathrm{~L}$ $105 \mathrm{~kW}$ TDI engine. The scaling approach consisted of matching the maximum torque-speed curve of the Jetta $2.0 \mathrm{~L}$ engine map to the maximum torque-speed curve of a target engine - 
in this case a 2013 Ford Transit Connect - and then using these scale factors to generate the remaining map (27).

\begin{tabular}{|c|c|c|c|c|c|}
\hline Engine Map & Vehicle Type & Vehicle Class & $\%$ of Fleet & Extrapolation & Source \\
\hline $\begin{array}{l}\text { Geo 1.0L } \\
41 \mathrm{~kW} \mathrm{SI}\end{array}$ & \multirow{3}{*}{ Cars } & Supermini & $34.4 \%$ & None & Advisor (27) \\
\hline $\begin{array}{c}\text { Saturn 1.9L } \\
\text { 95kW SI } \\
\end{array}$ & & $\begin{array}{l}\text { Lower } \\
\text { Medium }\end{array}$ & $26.9 \%$ & None & Advisor (27) \\
\hline $\begin{array}{l}\text { Jetta } 2.0 \mathrm{~L} \\
95 \mathrm{~kW} \text { TDI }\end{array}$ & & $\begin{array}{c}\text { Upper } \\
\text { Medium, } \\
\text { Executive }\end{array}$ & $19.7 \%$ & Low RPM & $\begin{array}{c}\text { Ecomodder.com } \\
\text { (14) }\end{array}$ \\
\hline $\begin{array}{c}\text { Scaled Jetta } \\
\text { 2.0L 95kW TDI }\end{array}$ & Vans & All Vans & $11.5 \%$ & Low RPM & $\begin{array}{l}\text { Scaled version of } \\
\text { Jetta } 2.0 \mathrm{~L}(14)\end{array}$ \\
\hline $\begin{array}{c}\text { Cummins M11 } \\
246 \mathrm{~kW} \text { CI }\end{array}$ & HGVs & All HGVs & $7.5 \%$ & None & Advisor (27) \\
\hline
\end{tabular}

Table 5: Engine map details.

A representative vehicle model was assigned to each engine map according to the quality and availability of its specifications online (Table 6). In several instances, the selection process simply reduced to the availability of gear ratio data.

\begin{tabular}{|c|c|}
\hline Engine Map & Vehicle Model \\
\hline Geo 1.0L 41kW SI & 1999 Geo Metro Hatchback \\
\hline Saturn 1.9L 95kW SI & 2002 Saturn S Series SL2 \\
\hline Jetta 2.0L 95kW TDI & 2009 Jetta Sportswagon \\
\hline Scaled Jetta 2.0L 95kW TDI & 2013 125PS Ford Transit Custom \\
\hline \multirow{3}{*}{ Cummins M11 246kW CI } & 2013 Scania Box Truck (Rigid Truck) \\
\cline { 2 - 2 } & $\begin{array}{c}\text { 2013 Scania G-Series Streamline Truck } \\
\text { (Articulated Truck) }\end{array}$ \\
\hline
\end{tabular}

Table 6: Engine map assignments.

\section{Vehicle Parameters}

Vehicle specifications including weight, length, dynamic tyre radius, drag area, and gear ratios were established during the map assignment process. Other parameters, such as accessory losses, were not available for any of the models: therefore approximate values from $(16,28)$ were used instead. A complete list of the final vehicle dimensions and gear ratios is provided in Appendix B.

\section{Gear Selection}

The model uses a 'fuel optimal' gear selection scheme suggested by Kesting et al. (17). This framework is an idealistic representation of driving behaviour. Depending on the state parameters (e.g. speed, acceleration), drivers perform gear shifts such that they are always in their most fuel efficient gear:

$$
G(v, a)=\operatorname{argmin}\left[Q\left(v, a, G^{\prime}\right)\right]
$$


where $Q\left(v, a, G^{\prime}\right)$ represents the fuel consumption for all of the possible gears $G^{\prime}$. At each time-step, the model evaluates Equation 10 in order to find and select the most efficient gear for each vehicle.

\section{Verification}

Simulations were conducted in order to verify the performance of the fuel consumption model over an exhaustive range of traffic densities. The simulated fuel economies for each engine map are compared against published 'city' and 'highway' fuel economies in Table 7. In all but one case (1999 Geo Metro) the simulated fuel consumptions fell within the measured fuel economy ranges for these vehicles. This comparison is very approximate, because the drive cycles used for measuring 'Highway' and 'City' fuel economy bear little resemblance to the simulated vehicle duty cycles for single carriageway roads. Nevertheless, the fact that the simulated fuel consumption values are bracketed by the published ranges gives a reasonable level of confidence in the model.

\begin{tabular}{|c|c|c|c|c|}
\hline Vehicle Class & $\begin{array}{c}\text { Simulated Fuel } \\
\text { Economy at 2.5 } \\
\text { veh/Lane.km } \\
\text { (L/100km) }\end{array}$ & $\begin{array}{c}\text { Simulated Fuel } \\
\text { Economy at 45 } \\
\text { veh/Lane.km } \\
\text { (L/100km) }\end{array}$ & $\begin{array}{c}\text { Highway } \\
\text { Fuel Economy } \\
\text { (L/100km) }\end{array}$ & $\begin{array}{c}\text { City } \\
\text { Fuel Economy } \\
\text { (L/100km) }\end{array}$ \\
\hline $\begin{array}{c}\text { 1999 Geo Metro } \\
\text { Hatchback }\end{array}$ & 5.7 & 5.2 & 4.3 & 5.4 \\
\hline $\begin{array}{c}\text { 2002 Saturn S } \\
\text { Series SL2 }\end{array}$ & 6.3 & 6.0 & 5.3 & 6.0 \\
\hline $\begin{array}{c}\text { 2009 Jetta } \\
\text { Sportwagon }\end{array}$ & 5.7 & 5.0 & 4.8 & 9.9 \\
\hline $\begin{array}{c}\text { 2013 125PS Ford } \\
\text { Transit }\end{array}$ & 9.4 & 7.8 & 7.4 & 29.4 to $47.0^{1}$ \\
\hline $\begin{array}{c}\text { 2013 Scania Box } \\
\text { Truck }\end{array}$ & 29.5 & 36.1 & \multicolumn{2}{|c|}{31.4 to $58.8^{1}$} \\
\hline $\begin{array}{c}\text { 2013 Scania } \\
\text { G-Series } \\
\text { Streamline } \\
\text { Truck }\end{array}$ & 39.6 & 48.2 & & \\
\hline
\end{tabular}

Table 7: Simulated fuel economies as compared with manufacturer data from $(29,30)$.

${ }^{1}$ Estimates vary with payload.

\section{Parametric Study}

\subsection{Passing Opportunity Analysis}

The study of single carriageway traffic behaviour necessitated the simulation of long road sections (of sufficient length for the calculations to converge) with realistic passing zone lengths. Therefore a procedure was developed in which single carriageway roads with representative passing opportunities were synthesized using probability distributions of passing lengths, measured on the five road links listed in Table 3. 
Sample 'passing' and 'no-passing' probability distributions measured for road link AL1346 are shown in Figure 8 along with fitted Weibull probability distributions. Each road link was found to exhibit unique passing zone distributions. Link AL1346 has a large number of short passing and no-passing zones. Other links display fewer, longer zones resulting in less skewed distributions. Because of the discrete lengths of road sections, the road synthesis procedure can only generate roads with passing percentages of $88 \%, 84 \%, 72 \%, 62 \%$, and $37 \%$. ( $100 \%$ and $0 \%$ roads are also feasible, although not representative of UK roads.) Further details regarding the passing opportunity analysis are provided by Wilson et al. (18).

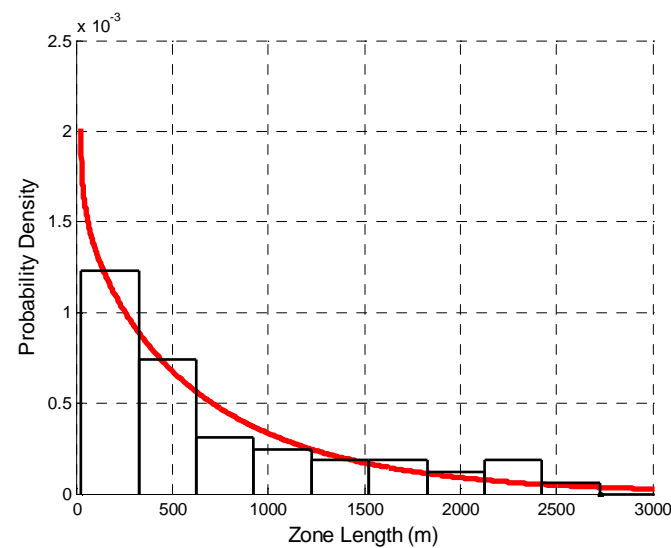

(a)

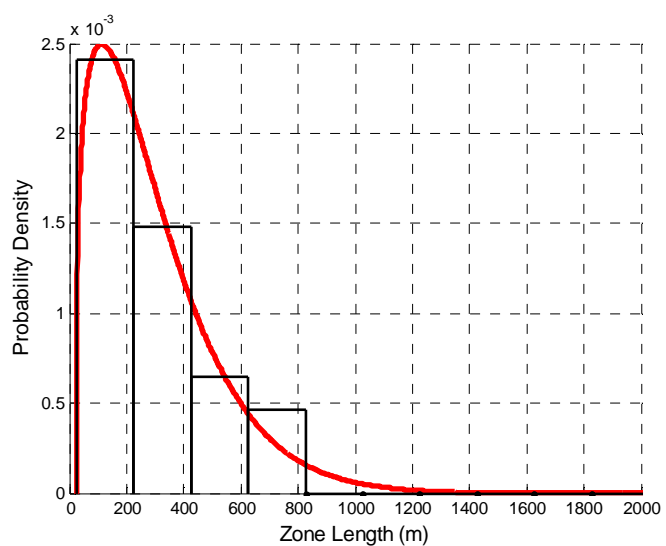

(b)

Figure 8: Probability distributions of passing lengths, measured for link AL1346, with fitted Weibull Distributions. (a) Passing Zones; (b) No-passing zones.

\subsection{Simulation Scenarios}

The DfT consultation (1) indicated that the speed limit for HGV's greater than 7.5 tonnes may be increased from $40 \mathrm{mph}$ to $50 \mathrm{mph}$ or from $40 \mathrm{mph}$ to $45 \mathrm{mph}$ on single carriageways. This study considered the effects of the larger DfT speed limit modification - an increase from $40 \mathrm{mph}$ to $50 \mathrm{mph}$. The consequences of increasing the speed limit to $45 \mathrm{mph}$ were expected to follow similar trends, though to a lesser magnitude. To evaluate the effects of this change on fleet behaviour, the study evaluated scenarios in which traffic density and HGV desired speeds were varied.

\section{Varying Traffic Densities}

The study simulated an exhaustive range of traffic densities by varying the number of vehicles on the roads. The model simulated densities ranging from 1.1 veh/lane. $\mathrm{km}$ to 112.5 veh/lane.km. The lower value represents free-flow traffic whereas the higher value represents bumper-to-bumper congestion.

\section{Varying HGV Speed Limit}

The study simulated the change in HGV speed limits by adjusting the probability distributions of the HGV desired velocities $v_{0}$. For the $40 \mathrm{mph}$ HGV speed limit scenario, fleet 
desired velocities were set to the desired velocities in the calibrated, single carriageway model (see Table 4). This is because the $40 \mathrm{mph}$ scenario represents the current, standard UK road conditions which were considered throughout the development process of the single carriageway model. In simulating the 50mph HGV speed limit scenario, the study implemented an 'idealized driver' approach. Desired velocities were set precisely to $50 \mathrm{mph}$ with zero standard deviation, ensuring that HGV drivers never exceed the speed limit (Table $8)^{2}$.

\begin{tabular}{|c|c|c|c|c|}
\hline Scenario & $\begin{array}{c}\text { Rigid } \\
\text { Truck } \\
\text { Mean } \boldsymbol{v}_{\mathbf{0}} \\
\text { (mph) }\end{array}$ & $\begin{array}{c}\text { Rigid Truck } \\
\text { Standard } \\
\text { Deviation } \boldsymbol{v}_{\mathbf{0}} \\
\text { (mph) }\end{array}$ & $\begin{array}{c}\text { Articulated } \\
\text { Truck } \\
\text { Mean } \boldsymbol{v}_{\mathbf{0}} \\
\text { (mph) }\end{array}$ & $\begin{array}{c}\text { Articulated } \\
\text { Truck } \\
\text { Standard } \\
\text { Deviation } \boldsymbol{v}_{\mathbf{0}} \\
\text { (mph) }\end{array}$ \\
\hline $\begin{array}{c}\text { 40mph Speed } \\
\text { Limit }\end{array}$ & 46 & 9.6 & 44 & 8.2 \\
\hline $\begin{array}{c}\text { 50mph Speed } \\
\text { Limit }\end{array}$ & 50 & 0 & 50 & 0 \\
\hline
\end{tabular}

Table 8: Desired velocity distributions used during the final study.

\subsection{Congestion and Passing Frequency Metrics}

The level of traffic congestion was quantified using the metric developed by Morrison et al. (11). This defines congestion $C$ as the extent to which vehicles are restricted in reaching their desired velocities:

$$
C=1-\frac{1}{N} \sum_{n=1}^{N} \frac{v_{n}}{v_{0, n}}
$$

where, $v_{n}$ and $v_{0, n}$ are the average and desired velocities of the $n^{t h}$ vehicle, respectively.

A congestion value of $C=0$ indicates free-flow conditions whereas $C=1$ indicates stationary traffic. This approach allows comparison of congestion levels between different traffic states.

Passing behaviour was quantified using a single metric: the fleet-averaged passes per vehicle.hour. This passing frequency metric provides an intuitive way to quantify the passing behaviour of entire vehicle fleets.

\footnotetext{
${ }^{2}$ Without any 50mph HGV free-flow statistics for single carriageways, the 'idealized driver' assumption reflects a conservative approach to approximating $v_{0}$ for the $50 \mathrm{mph}$ speed limit scenario. Increased speed limits are widely known to result in increased fleet speeds with some vehicles exceeding the speed limit, though the precise numerical relationship is less clear (31). The effects of speed limit changes on velocity distributions are further uncertain: studies have found reductions in standard deviations for both higher and lower speed limits. The HCM (32) suggests that the posted speed limit be used as a surrogate in the absence of free-flow speed field data - the approach which was adopted here.
} 


\subsection{Results \& Discussion}

\section{Impact of Raised HGV Speed Limit on the Fundamental Diagram}

Figure 9 depicts the fundamental diagram for both the $40 \mathrm{mph}$ and $50 \mathrm{mph}$ simulation scenarios. At very low congestion levels (towards the right of the chart), vehicle interactions are infrequent. Consequently, vehicle speeds are approximately equal to their desired velocities - the $50 \mathrm{mph}$ scenario velocities being on average around $6 \mathrm{mph}$ higher than the $40 \mathrm{mph}$ scenario velocities. This observation is particularly pertinent to single carriageways, where flow rates tend to be low. As traffic approaches bound flow (at the top of the chart), vehicle interactions increase and faster fleet vehicles begin to platoon behind the slowest vehicles. The extent to which traffic is slowed depends on the speeds of the slowest moving vehicles - the $40 \mathrm{mph}$ HGVs cause distinctly more traffic delays than the $50 \mathrm{mph}$ HGVs. When congestion is high (left of the chart) all vehicles are restricted in their speeds: therefore HGV speed limits have no influence on traffic behaviour in this region.

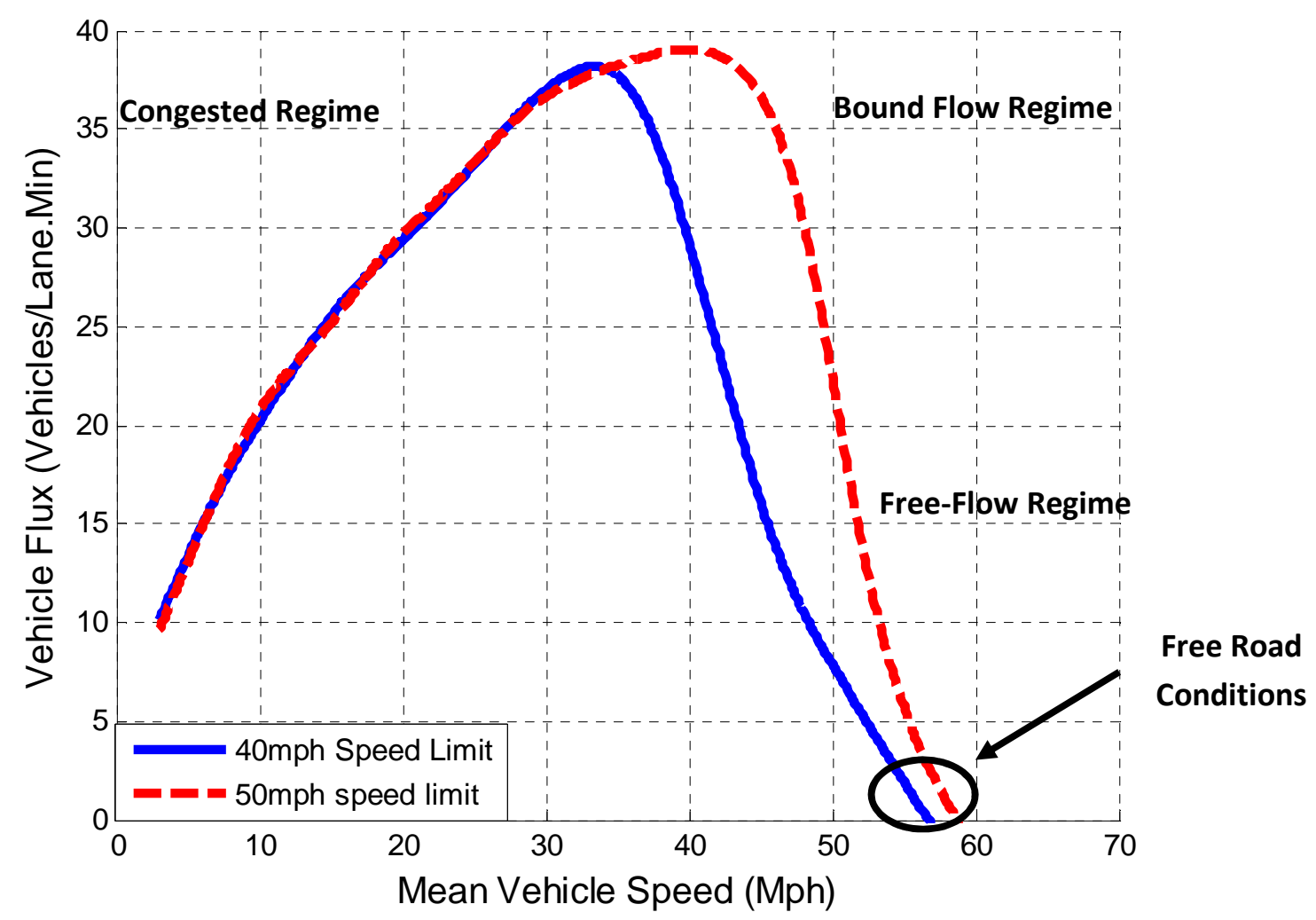

Figure 9: Fundamental diagrams for $40 \mathrm{mph}$ and $50 \mathrm{mph}$ cases.

\section{Impact of Raised HGV Speed Limit on Traffic Congestion}

Figures 10 shows the congestion levels for both simulated traffic scenarios using the congestion metric $C$, defined in eq. (11). The effects of speed limit on congestion are most apparent in the free-flow/bound-flow transition region ( 20 veh/lane.km), where drivers are restricted most by the slowest moving vehicles. In this region, congestion is reduced by 
an average of $31.5 \%$ and up to $37.3 \%$ using the $50 \mathrm{mph}$ HGV speed limit. This could yield significant economic benefits to the travelling public.

The two curves converge for densities above 40 veh/lane.km where the HGV speed limit has a negligible effect, because congestion is so high. Note, however, that single carriageways rarely reach such high densities (32).

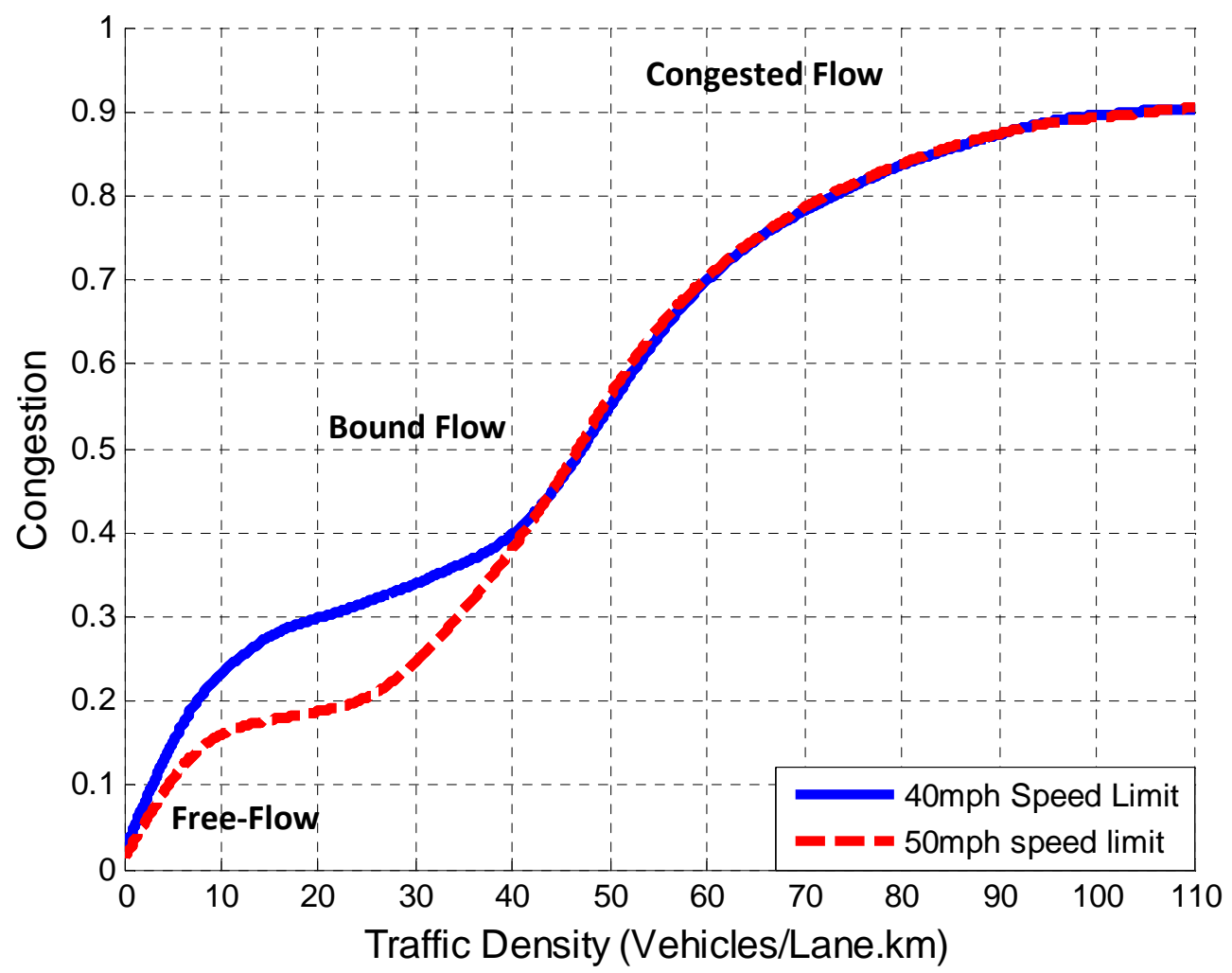

Figure 10: Congestion diagram for both traffic scenarios.

\section{Passing}

Figure 11 depicts the passing frequencies for both the $40 \mathrm{mph}$ and $50 \mathrm{mph}$ scenarios as a function of traffic density. Passing is considerably more frequent in the $40 \mathrm{mph}$ scenario than the $50 \mathrm{mph}$ scenario. Vehicles only consider overtaking if the leading vehicle restricts their ability to reach desired speeds. The wider distribution of desired speeds in the $40 \mathrm{mph}$ case increases the number of these desirable passing states. Furthermore, drivers need smaller passing gaps to overtake slower vehicles. This makes passing in the $40 \mathrm{mph}$ scenario more feasible than in the 50mph scenario, especially in medium densities (20 to 40 veh/lane.km).

These passing results could have traffic safety implications; however it is only possible to speculate on these without further research. According to (33), the number of fatal accidents in the UK involving vehicles passing HVGs averages 5 per year, which is relatively low. The maximum realizable benefit from reducing single lane passing would therefore be to eliminate these 5 annual fatalities. However, while the $50 \mathrm{mph}$ scenario may lead to fewer 
passing manoeuvres, the severity of the passing-related accidents would likely increase perhaps leading to even more fatalities. Therefore the overall safety outcome is difficult to predict.

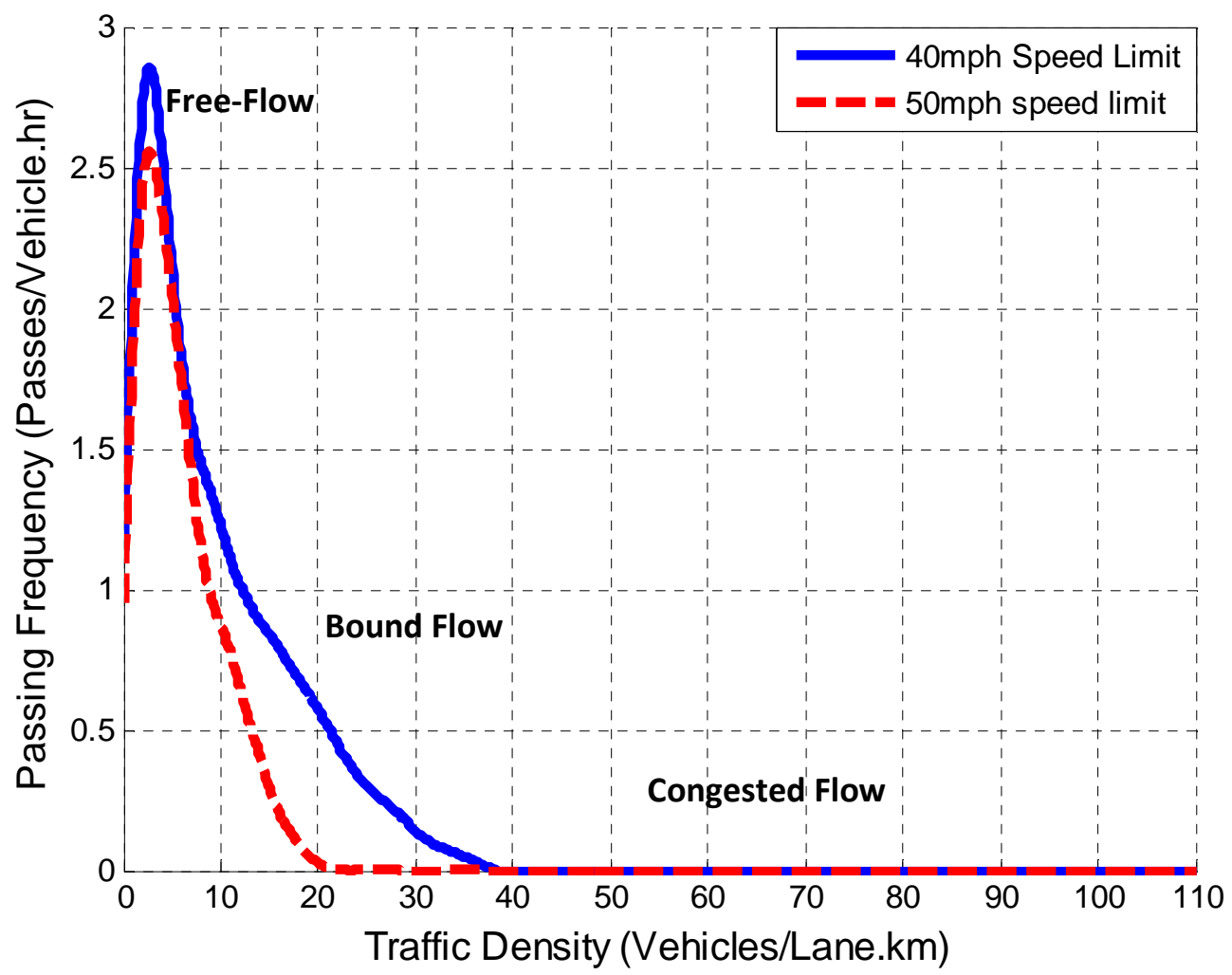

Figure 11: Passing frequency for both scenarios as a function of traffic density.

\section{Impact of Raised HGV Speed Limit on Fuel Consumption}

Figure 12 depicts the average fuel consumption of the entire vehicle fleet as a function of traffic density for both HGV speed limit scenarios. In the free-flow region, fuel consumption is highest in the $50 \mathrm{mph}$ scenario as vehicles are travelling faster - thus having to overcome greater aerodynamic drag. Fuel consumptions in the bound flow region become more comparable as the differences between the two fleet velocities decrease. Fleet fuel consumption is on average $0.5 \mathrm{~L} / 100 \mathrm{~km}$ higher when using the $50 \mathrm{mph}$ HGV speed limit in this region. However, this increase is mostly due to HGVs, as their fuel consumption increases by an average of $2.0 \mathrm{~L} / 100 \mathrm{~km}$. In the congested region, the sharp rise in consumption is related to the presence of stop-start traffic jams, as the power required to overcome inertia increases. The $50 \mathrm{mph}$ fuel consumption is slightly higher than the $40 \mathrm{mph}$ fuel consumption in this region due to the higher accelerations present in the fleet (see (18)). However, this may be an artefact of the IDM as it is not obvious that drivers in heavily congested traffic accelerate harder if there is a higher speed limit. It is probably more realistic to assume that the fuel consumption is unchanged in this region. 


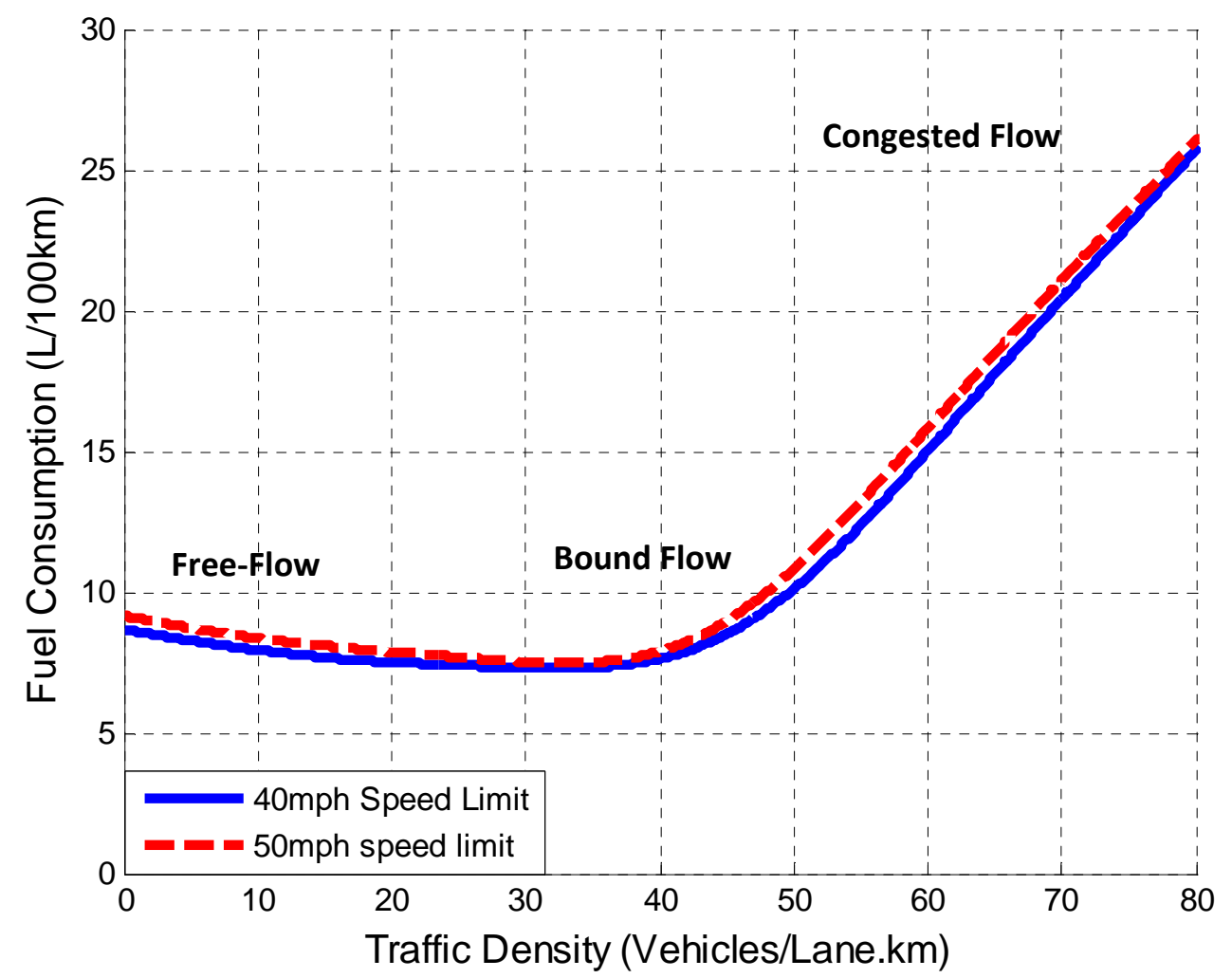

Figure 12: Fleet fuel consumption diagram for both scenarios.

\section{Conclusions}

(i) A microscopic, single carriageway model was developed by combining a single-lane car following model (Enhanced IDM) and a single carriageway passing model (Time to Collision). This model was calibrated and validated against UK single carriageway data, ensuring that simulations accounted for a diverse range of road conditions. Fuel consumption was calculated through the implementation of an energy model, gear selection scheme, and engine characteristic maps. Results were compared with published manufacturer fuel economies to verify they were within range.

(ii) Traffic in the free-flow region is most influenced by the slowest vehicles on the road. Congestion is reduced as a result of narrowing the distribution of vehicle speeds within the fleet. The proposed $50 \mathrm{mph}$ speed limit on single carriageway roads is therefore expected to reduce traffic congestion by as much as $37.3 \%$.

(iii) Passing frequencies are expected to reduce with the proposed $50 \mathrm{mph}$ speed limit, however, passing vehicles would likely be travelling at higher velocities. More work is therefore needed to fully understand the resulting safety implications. 
(iv) Fleet fuel consumptions rise by an average of $0.5 \mathrm{~L} / 100 \mathrm{~km}$ when using the $50 \mathrm{mph}$ HGV speed limit. This increase is mainly due to higher aerodynamic losses at the higher average speeds in the free- and bound-flow regimes.

In summary: the results from this study provide an argument in favour of the new, $50 \mathrm{mph}$ HGV speed limit: it would considerably reduce traffic congestion and its economic impacts. Fleet fuel consumption would rise, although only by a small margin. Improvements in traffic safety due to reduced passing were not thoroughly assessed in this study. A more detailed analysis of safety considerations is needed to determine whether the $50 \mathrm{mph}$ speed limit would increase or decrease the risk of casualties due to passing accidents. The effect is likely to be small.

\section{Acknowledgements}

The authors would like to thank Justin Bishop and Niall Martin of Cambridge University Engineering Department for providing valuable data. The authors would also like to thank Rachael Dillon of Freight Transport Association for suggesting the project.

This work was supported in part by the Centre for Sustainable Road Freight (SRF) and the Engineering and Physical Sciences Research Council (EPSRC) through Grant Ref EP/K00915X/1. At the time of writing, the members of the SRF were: Coca-Cola Enterprises, Denby Transport, DHL, Freight Transport Association, Haldex Brake Products, Goodyear Tires, John Lewis/Waitrose, Laing O'Rourke, Optrak, SDC Trailers, Tesco, Volvo Trucks, Warburtons, Wincanton. 


\section{References}

1. Examining the Speed Limit for HGV's Over 7.5 Tonnes on Single Carriageway Roads: A Consultation Document. Department for Transport; 2012 Nov.

2. Response to the Department for Transport's "Examining the Speed Limit for HGVs Over 7.5 Tonnes on Single Carriageway Roads. The Royal Society for the Prevention of Accidents; 2013.

3. Greenshields BD, Bibbins JR, Channing WS, Miller HH. A study of traffic capacity. Highway research board proceedings [Internet]. 1935 [cited 2013 Aug 22]. Available from: http://trid.trb.org/view.aspx?id=120649

4. Daiheng N. Traffic Flow Characteristics [Internet]. Lecture Notes in Traffic Flow Theory: A Unified Approach. 2013. Available from: http://people.umass.edu/ndh/TFT.html

5. Kerner BS, Rehborn H. Experimental properties of phase transitions in traffic flow. Physical Review Letters. 1997;79(20):4030.

6. Treiber M, Kesting A, Helbing D. Three-phase traffic theory and two-phase models with a fundamental diagram in the light of empirical stylized facts. Transportation Research Part B: Methodological. 2010;44(8):983-1000.

7. Bando M, Hasebe K, Nakanishi K, Nakayama A. Analysis of Optimal Velocity Model with Explicit Delay. arXiv preprint patt-sol/9805002. 1998;

8. Orosz G, Wilson RE, Stépán G. Traffic jams: dynamics and control. Philosophical Transactions of the Royal Society A: Mathematical, Physical and Engineering Sciences. 2010;368(1928):445579.

9. Wagner P. Fluid-dynamical and microscopic description of traffic flow: a data-driven comparison. Philosophical Transactions of the Royal Society A: Mathematical, Physical and Engineering Sciences. 2010;368(1928):4481-95.

10. Kesting A, Treiber M, Helbing D. Enhanced intelligent driver model to access the impact of driving strategies on traffic capacity. Philosophical Transactions of the Royal Society A: Mathematical, Physical and Engineering Sciences. 2010;368(1928):4585-605.

11. Morrison G, Roebuck RL, Cebon D. Effects of heavy vehicle size on traffic congestion. Proceedings of the Institution of Mechanical Engineers, Part C: Journal of Mechanical Engineering Science [Internet]. 2013 [cited 2013 Aug 22]; Available from: http://pic.sagepub.com/content/early/2013/08/01/0954406213493384.abstract

12. Farah $\mathrm{H}$, Bekhor $\mathrm{S}$, Polus $\mathrm{A}$, Toledo $\mathrm{T}$. A passing gap acceptance model for two-lane rural highways. Transportmetrica. 2009;5(3):159-72.

13. Ghods A. Microscopic Overtaking Simulation Model for Rural Two-lane Highways. [Ontario]: University of Waterloo;

14. Barth M, An F, Norbeck J, Ross M. Modal emissions modeling: A physical approach. Transportation Research Record: Journal of the Transportation Research Board. 1996;1520(1):81-8. 
15. Road Vehicle Emissions Factors - June 2009 [Internet]. Department for Transport; 2009. Available from: https://www.gov.uk/government/publications/road-vehicle-emission-factors2009

16. Hunt SW, Odhams AMC, Roebuck RL, Cebon D. Parameter measurement for heavy-vehicle fuel consumption modelling. Proceedings of the Institution of Mechanical Engineers, Part D: Journal of Automobile Engineering. 2011;225(5):567-89.

17. Treiber $\mathrm{M}$, Kesting A, Thiemann C. How much does traffic congestion increase fuel consumption and emissions? Applying a fuel consumption model to the NGSIM trajectory data. 87th Annual Meeting of the Transportation Research Board, Washington, DC. 2008.

18. Wilson G, Morrison G, Midgley W, Cebon D. The Relationship Between Speed Limit and Fleet Fuel Consumption on Minor Roads. Cambridge, UK.: Department of Engineering, University of Cambridge; 2013. Report No.: CUED/C-Mech/TR.103.

19. Harwood DW, Gilmore DK, Richard KR, Dunn JM, Sun C. NCHRP Report 605: Passing Sight Distance Criteria. Transportation Research Board of the National Academies, Washington, DC. 2008;

20. SPE0101 - Vehicle speeds on non built up roads by road type and vehicle type in Great Britain, annual from 2006. Department for Transport, 2012.

21. Kim J, Elefteriadou L. Estimation of capacity of two-lane two-way highways using simulation model. Journal of Transportation Engineering. 2009;136(1):61-6.

22. Highways Agency Network Journey Time and Traffic Flow Data [Internet]. Data.gov.uk. Available from: http://data.gov.uk/dataset/dft-eng-srn-routes-journey-times

23. SPE0102 - Free flow vehicle speeds on built-up roads by speed limit and vehicle type in Great Britain. Department for Transport, 2011.

24. Nezamuddin N, Crunkleton JL, Tarnoff PJ, Waller ST. Speed Distribution Profile of Traffic Data and Sample Size Estimation. Traffic Engineering \& Control. 2010;51(4).

25. Treiber M. Longitudinal Traffic Model: The IDM [Internet]. Available from: http://www.vwi.tudresden.de/ treiber/MicroApplet/IDM.html

26. Motor Industry Facts 2013 [Internet]. The Society of Motor Manufacturers and Traders; 2013. Available from: http://www.smmt.co.uk/wp-content/uploads/SMMT-2013-Motor-IndustryFacts-guide.pdf?9b6f83

27. Advisor: Advanced Vehicle Simulator [Internet]. Big Ladder Software; Available from: http://bigladdersoftware.com/advisor/

28. Gaines L, Levinson T, McConnell S. To Idle or Not to Idle: That is the Question. IL, USA: Argonne National Laboratory; 2010.

29. Auto Specs and Reviews [Internet]. Auto123.com. Available from: http://www.auto123.com/en/

30. 2013 Vehicle Technologies Market Report [Internet]. U.S. Department of Energy; 2013. Available from: http://cta.ornl.gov/vtmarketreport/index.shtml 
31. Kweon Y-J, Kockelman KM. Safety effects of speed limit changes: Use of panel models, including speed, use, and design variables. Transportation Research Record: Journal of the Transportation Research Board. 2005;1908(1):148-58.

32. Highway Capactiy Manual. Transportation Research Board; 2000.

33. Summersgill I, Buckle G, Robinson T, Smith S. HGV speed limit increase evaluation: final report. HGV speed limit increase evaluation: final report. 2012;1(1):1-32.

34. 1997 Geo Metro Performance Specs [Internet]. Motor Trend. Available from: http://www.motortrend.com/cars/1997/geo/metro/specifications

35. 2002 Saturn S-Series Review [Internet]. Edmunds.com. Available from: http://www.edmunds.com/saturn/s-series/2002

36. 2009 Volkswagen Jetta TDI SportWagen [Internet]. Yahoo Autos. Available from: http://autos.yahoo.com/volkswagen/jetta-sportwagen/2009/tdi/specifications.html

37. Ford Transit Custom iBrochure [Internet]. Ford. Available from: http://www.ford.co.uk/Hidden/iBrochure/Transit-Custom

38. Wong JY. Theory of ground vehicles. NJ, USA: John Wiley \& Sons; 2001.

39. Transmissions [Internet]. MetroWiki. Available from: http://themetrowiki.wikispaces.com/Transmission

40. S-Series Transmission Gear Ratios. SaturnSeries.net. 2012.

41. Gear Ratios: 2009 Volkswagen Jetta Sportwagen [Internet]. Vibrate Software. 2012. Available from:

http://www.vibratesoftware.com/html_help/2011/VW/2009/2009_VW_Jetta_Sportwagen.ht $\mathrm{m}$

42. Two New Ford Transit Engines [Internet]. The Auto Channel. Available from: www.theautochannel.com/news/2004/03/27/186760.html 


\section{Appendix A - Single Carriageway Model Parameters}

\begin{tabular}{|c|c|c|c|c|c|c|c|}
\hline Parameter & Symbol & $\begin{array}{c}\text { Data } \\
\text { Source }\end{array}$ & $\begin{array}{c}\text { Parameter } \\
\text { Form }\end{array}$ & Cars & Vans & $\begin{array}{c}\text { Rigid } \\
\text { Trucks }\end{array}$ & $\begin{array}{c}\text { Articulated } \\
\text { Trucks }\end{array}$ \\
\hline $\begin{array}{c}\text { Vehicle } \\
\text { Distribution } \\
\text { (\%) }\end{array}$ & None & $(20)$ & $\begin{array}{c}\text { Raw } \\
\text { Distribution }\end{array}$ & 81 & 11.5 & 4.65 & 2.85 \\
\hline $\begin{array}{c}\text { Vehicle Length } \\
\text { (m) }\end{array}$ & $L$ & $(10)$ & $\begin{array}{c}\text { Single } \\
\text { Value }\end{array}$ & 4.2 & 4.2 & 16.5 & 16.5 \\
\hline $\begin{array}{c}\text { Desired } \\
\text { Velocities } \\
\text { (m/s) }\end{array}$ & $v_{0}$ & $(20)$ & $\begin{array}{c}\text { Nitted } \\
\text { Normal } \\
\text { Distribution }\end{array}$ & $\begin{array}{c}\mu: 48 \\
\sigma: 9.5\end{array}$ & $\begin{array}{c}\mu: 48 \\
\sigma: 9.9\end{array}$ & $\begin{array}{c}\mu: 46 \\
\sigma: 9.6\end{array}$ & $\mu: 44$ \\
\hline $\begin{array}{c}\text { Desired Time } \\
\text { Headway (s) }\end{array}$ & $T$ & $(10)$ & $\begin{array}{c}\text { Single } \\
\text { Value }\end{array}$ & 1.5 & 1.5 & 2 & 2 \\
\hline $\begin{array}{c}\text { Max Acc. } \\
\text { (m/s } \text { ) }\end{array}$ & $a$ & $(10)$ & $\begin{array}{c}\text { Single } \\
\text { Value }\end{array}$ & 1.4 & 1.4 & 0.7 & 0.7 \\
\hline $\begin{array}{c}\text { Comf. Dec. } \\
\text { (m/s } \text { ) }\end{array}$ & $b$ & $(10)$ & $\begin{array}{c}\text { Single } \\
\text { Value }\end{array}$ & 2 & 2 & 2 & 2 \\
\hline $\begin{array}{c}\text { Jam Distance } \\
\text { (m) }\end{array}$ & $s_{o}$ & $(10)$ & $\begin{array}{c}\text { Single } \\
\text { Value }\end{array}$ & 2 & 2 & 4 & 4 \\
\hline $\begin{array}{c}\text { Free } \\
\text { Acceleration } \\
\text { Exponent }\end{array}$ & $\delta$ & $(10)$ & $\begin{array}{l}\text { Single } \\
\text { Value }\end{array}$ & 4 & 4 & 4 & 4 \\
\hline $\begin{array}{c}\text { Coolness } \\
\text { Factor }\end{array}$ & $c$ & $(10)$ & $\begin{array}{c}\text { Single } \\
\text { Value }\end{array}$ & 0.99 & 0.99 & 0.99 & 0.99 \\
\hline
\end{tabular}

Table A1: Uncalibrated enhanced IDM vehicle following parameters. The single carriageway model also incorporates the calibration factors detailed in Table 3. 


\begin{tabular}{|c|c|c|c|c|c|c|c|}
\hline Parameter & Symbol & $\begin{array}{c}\text { Data } \\
\text { Source }\end{array}$ & $\begin{array}{c}\text { Parameter } \\
\text { Form }\end{array}$ & Cars & Vans & $\begin{array}{c}\text { Rigid } \\
\text { Trucks }\end{array}$ & $\begin{array}{c}\text { Articulated } \\
\text { Trucks }\end{array}$ \\
\hline $\begin{array}{c}\text { Critical Time } \\
\text { to Collision (s) }\end{array}$ & $T T C_{\text {crit }}$ & $(13)$ & $\begin{array}{c}\text { Normal } \\
\text { Distribution }\end{array}$ & $\begin{array}{c}\mu: 1.5 \\
\sigma: 1\end{array}$ & $\begin{array}{c}\mu: 1.5 \\
\sigma: 1\end{array}$ & N/A & N/A \\
\hline $\begin{array}{c}\text { Max Velocity } \\
\text { (m/s) }\end{array}$ & $v^{\max }$ & $(13)$ & $\begin{array}{c}\text { Single } \\
\text { Value }\end{array}$ & 55 & 55 & N/A & N/A \\
\hline $\begin{array}{c}\text { Desired } \\
\text { Overtaking } \\
\text { Velocity (m/s) }\end{array}$ & $v^{\text {des-ov }}$ & $(13)$ & $\begin{array}{c}\text { Single } \\
\text { Value }\end{array}$ & $\begin{array}{c}v_{L V}+ \\
4.2\end{array}$ & $\begin{array}{c}v_{L V}+ \\
4.2\end{array}$ & N/A & N/A \\
\hline $\begin{array}{c}\text { Desire to } \\
\text { Overtake } \\
\text { Threshold } \\
\text { (m/s) }\end{array}$ & $v_{t h r e s h}$ & $(21)$ & $\begin{array}{c}\text { Single } \\
\text { Value }\end{array}$ & 2.22 & 2.22 & N/A & N/A \\
\hline $\begin{array}{c}\text { Max Acc. } \\
\text { (m/s } \text { ) }\end{array}$ & $a^{m a x}$ & $(10)$ & $\begin{array}{c}\text { Single } \\
\text { Value }\end{array}$ & 1.4 & 1.4 & 0.7 & 0.7 \\
\hline $\begin{array}{c}\text { Fraction of } \\
\text { Max Acc. } \\
\text { Employed }\end{array}$ & $k$ & $(13)$ & $\begin{array}{c}\text { Single } \\
\text { Value }\end{array}$ & 0.7 & 0.7 & N/A & N/A \\
\hline $\begin{array}{c}\text { Perception } \\
\text { Time (s) }\end{array}$ & $t_{1}$ & $(13)$ & $\begin{array}{c}\text { Single } \\
\text { Value }\end{array}$ & 1.5 & 1.5 & N/A & N/A \\
\hline $\begin{array}{c}\text { Pull-back Time } \\
\text { (s) }\end{array}$ & $t_{4}$ & $(13)$ & $\begin{array}{c}\text { Single } \\
\text { Value }\end{array}$ & 3 & 3 & N/A & N/A \\
\hline $\begin{array}{c}\text { Headway Pull- } \\
\text { back (m) }\end{array}$ & $H W^{p b}$ & $(13)$ & $\begin{array}{c}\text { Single } \\
\text { Value }\end{array}$ & 25 & 25 & 25 & 25 \\
\hline
\end{tabular}

Table A2: Passing model parameters used in the single carriageway model. 


\section{Appendix B - Fuel Consumption Model Parameters}

\begin{tabular}{|c|c|c|c|c|c|c|}
\hline Parameter & $\begin{array}{c}1999 \text { Geo } \\
\text { Metro } \\
\text { Hatchback }\end{array}$ & $\begin{array}{l}2002 \text { Saturn } \\
\text { S-Series SL2 }\end{array}$ & $\begin{array}{l}2009 \text { Jetta } \\
\text { Sportwagon }\end{array}$ & $\begin{array}{c}2013 \\
125 P S \text { Ford } \\
\text { Transit }\end{array}$ & $\begin{array}{l}2013 \text { Scania } \\
\text { Box Truck }\end{array}$ & $\begin{array}{l}2013 \text { Scania } \\
\text { G-Series } \\
\text { Streamline } \\
\text { Truck }\end{array}$ \\
\hline $\begin{array}{c}\text { Vehicle } \\
\text { Distribution } \\
(\%)\end{array}$ & 34.4 & 26.9 & 19.7 & 11.5 & 4.65 & 2.85 \\
\hline Length, $L(\mathrm{~m})$ & 3.8 & 4.5 & 4.6 & 5.4 & 9.0 & 16.5 \\
\hline $\begin{array}{c}\text { Kerb Weight, } \\
\text { (kg) }\end{array}$ & 830 & 1066 & 1490 & 1836 & 5000 & 14900 \\
\hline $\begin{array}{c}\text { Final Weight, } m \\
\text { (kg) }\end{array}$ & 1030 & 1266 & 1690 & 2636 & $25000 *$ & $44000 *$ \\
\hline $\begin{array}{c}\text { Dynamic Tyre } \\
\text { Radius, } r_{d y n}(\mathrm{~m})\end{array}$ & 0.30 & 0.30 & 0.31 & 0.33 & 0.51 & 0.51 \\
\hline
\end{tabular}

Table B1: Vehicle properties. Data taken from (10,34-37)

* Refers to laden weight. Unladen trucks use kerb weights.

\begin{tabular}{|c|c|c|c|c|c|c|}
\hline Parameter & $\begin{array}{c}\text { 1999 Geo } \\
\text { Metro } \\
\text { Hatchback }\end{array}$ & $\begin{array}{c}\text { 2002 Saturn } \\
\text { S-Series SL2 }\end{array}$ & $\begin{array}{c}\text { 2009 Jetta } \\
\text { Sportwagon }\end{array}$ & $\begin{array}{c}\text { 2013 125PS } \\
\text { Ford Transit }\end{array}$ & $\begin{array}{c}\text { 2013 Scania } \\
\text { Box Truck }\end{array}$ & $\begin{array}{c}\text { 2013 Scania } \\
\text { G-Series } \\
\text { Streamline } \\
\text { Truck }\end{array}$ \\
\hline $\begin{array}{c}\text { Drag Term, } \\
\boldsymbol{C}_{\boldsymbol{d}} \boldsymbol{A} \mathbf{~ m}^{2}\end{array}$ & 0.70 & 0.75 & 0.93 & 1.80 & 3.95 \\
\hline $\begin{array}{c}\text { Rolling } \\
\text { Resistance } \\
\text { Coefficients, } \\
\left(\boldsymbol{\mu}_{\mathbf{0}}, \boldsymbol{\mu}_{\mathbf{1}}\right)\end{array}$ & $(0.0136,4 \mathrm{e}-8)$ & $(0.0136,4 \mathrm{e}-8)$ & $(0.0136,4 \mathrm{e}-8)$ & $(0.0136,4 \mathrm{e}-8)$ & $(0.0136,4 \mathrm{e}-8)$ & $(0.0136,4 \mathrm{e}-8)$ \\
\hline $\begin{array}{c}\text { Accessory } \\
\text { Losses, } \\
\mathbf{P}_{\text {acc }}(\mathrm{kW})\end{array}$ & 3 & 3 & 3 & 3 & 45 \\
\hline $\begin{array}{c}\text { Transmission } \\
\text { Efficiency, } \\
\boldsymbol{\eta}\end{array}$ & 0.90 & 0.90 & 0.90 & 0.90 & 0.90 \\
\hline
\end{tabular}

Table B2: Energy consumption model parameters. Data taken from (10,34-38).

\begin{tabular}{|c|c|c|c|c|}
\hline Gear Ratios & $\begin{array}{c}\text { 1999 Geo Metro } \\
\text { Hatchback }\end{array}$ & $\begin{array}{c}\text { 2002 Saturn S } \\
\text { Series SL2 }\end{array}$ & $\begin{array}{c}\text { 2009 Jetta } \\
\text { Sportwagon }\end{array}$ & $\begin{array}{c}\text { 2013 125PS Ford } \\
\text { Transit }\end{array}$ \\
\hline $\begin{array}{c}\text { Final Drive } \\
\text { Gear }\end{array}$ & 4.44 & 4.06 & 3.45 & 5.13 \\
\hline $\mathbf{1}^{\text {st }}$ Gear & 3.42 & 3.25 & 3.77 & 4.20 \\
\hline 2 $^{\text {nd }}$ Gear & 1.89 & 1.95 & 2.09 & 2.24 \\
\hline 3 $^{\text {rd }}$ Gear & 1.28 & 1.42 & 1.32 & 1.37 \\
\hline 4 $^{\text {th }}$ Gear & 0.91 & 1.03 & 0.98 & 1.00 \\
\hline $\mathbf{5}^{\text {th }}$ Gear & 0.76 & 0.73 & 0.76 & 0.76 \\
\hline $6^{\text {th }}$ Gear & None & None & 0.63 & None \\
\hline
\end{tabular}

Table B3: Gear ratios for cars and vans (39-42). 


\begin{tabular}{|c|c|}
\hline Gear Ratios & Scania Trucks \\
\hline Final Drive Gear & 4.33 \\
\hline $\mathbf{1}^{\text {st }}$ Gear & 11.71 \\
\hline $\mathbf{2}^{\text {nd }}$ Gear & 8.20 \\
\hline $\mathbf{3}^{\text {rd }}$ Gear & 6.06 \\
\hline $\mathbf{4}^{\text {th }}$ Gear & 4.49 \\
\hline $\mathbf{5}^{\text {th }}$ Gear & 3.32 \\
\hline $\mathbf{6}^{\text {th }}$ Gear & 2.46 \\
\hline $\mathbf{7}^{\text {th }}$ Gear & 1.82 \\
\hline $\mathbf{8}^{\text {th }}$ Gear & 1.35 \\
\hline $\mathbf{9}^{\text {th }}$ Gear & 1.00 \\
\hline $\mathbf{1 0}^{\text {th }}$ Gear & 0.74 \\
\hline
\end{tabular}

Table B4: Gear ratios for rigid and articulated trucks [31]. 